\title{
Expression of Intrapulmonary Surfactant Apoprotein-A in Autopsied Lungs: Comparative Study of Cases with or without Pulmonary Hypoplasia
}

\author{
HIDEKI MINOWA, YUKIHIRO TAKAHASHI, CHIHARU KAWAGUCHI, TOSHIYUKI SADOU, \\ NOBORU KONISHI, TOSHIYA NISHIKUBO, AND AKIRA YOSHIOKA \\ Division of Neonatal Intensive Care [H.M., Y.T., C.K., T.S., A.Y.] and Second Department of Pathology \\ [N.K.], Nara Medical University Hospital, Kashihara City, Nara, Japan; and Neonatal Intensive Care \\ Unit, Perinatal Medical Center, Nara Prefectural Nara Hospital, Nara City, Nara, Japan [T.N.]
}

\begin{abstract}
TBST
To investigate the functional maturity of the lungs of infants
with pulmonary hypoplasia, we measured the expression of
surfactant apoprotein-A (SP-A) in the autopsied lungs. Autopsied
lungs were taken from 16 infants who died at birth or soon after.
A lung-to-body weight ratio of less than $1.2 \%$ was defined as
pulmonary hypoplasia. Eight infants were classified as belonging
to the normal group, and eight as belonging to the pulmonary
hypoplasia group. Many of the pulmonary hypoplasia group were
complicated not only by pulmonary hypoplasia, but also by
amniotic fluid volume abnormalities or an anatomical malforma-
tion. We measured the expression of SP-A immunologically
using murine anti-human SP-A MAb in the autopsied lung tissue,
and subjected the tissue to SP-A staining by the direct staining
method. The expression of SP-A was assessed as one of four
grades: - , \pm , $1+, 2+$. The staining intensity of SP-A was high
at $1+$ or stronger in five infants of the normal group. SP-A
\end{abstract}
ABSTRACT

The alveolar lining is composed of type I and type II epithelial cells. Human pulmonary surfactants are lipid-protein complexes (lipoproteins) synthesized in type II cells. These surfactants are secreted into the alveolar space in order to cover the surface of alveoli and thus reduce alveolar surface tension. The functional expression of pulmonary surfactants requires specific proteins (apoproteins). To date, four types of surfactant apoproteins (SP) have been identified: SP-A, SP-B, SP-C, and SP-D. Of these, SP-A is the most prevalent form of SP (1). SP-A is a hydrophilic glycoprotein with a molecular weight of approximately 28-36 $\mathrm{kD}$, and the level of SP-A in the amniotic fluid, gastric juice, and respiratory aspirate is a useful indicator of the functional maturity of fetal and neonatal lung tissue $(2,3)$.

In the present study, to assess the functional maturity of the lungs of infants with pulmonary hypoplasia, we measured the

Received January 17, 2000; accepted June 14, 2000.

Correspondence and reprint requests: Yukihiro Takahashi, Department of Pediatrics, Nara Medical University Hospital, 840 Shijo-cho, Kashihara City, Nara, Japan. expression was significantly reduced, however, in all infants of the pulmonary hypoplasia group except for one infant with normal amniotic fluid volume and relatively mild pulmonary hypoplasia. There was a significant negative correlation between the staining intensity of SP-A and two factors: pulmonary hypoplasia and abnormal amniotic fluid volume $(p=0.039$ and $p=$ 0.0063 , respectively). In the present study, we demonstrated that SP-A expression was significantly reduced in infants with pulmonary hypoplasia. We speculate that the functional maturity of the lungs of infants with pulmonary hypoplasia is also suppressed. (Pediatr Res 48: 674-678, 2000)

\section{Abbreviations}

SP-A, surfactant apoprotein-A

RAC, radial alveolar count

RDS, respiratory distress syndrome expression of SP-A immunohistologically using murine antihuman SP-A MAb in the autopsied lungs of infants who died at birth or soon after.

\section{METHODS}

Subjects. Autopsied lungs were taken from 16 infants at some point during a 21-y period between November 1976 and February 1998. Of the 16 infants, 14 came from the Division of Neonatal Intensive Care or the Department of Gynecology and Obstetrics at our hospital. These subjects had died at birth or within $5 \mathrm{~d}$ of birth. The remaining two infants came from the Neonatal Intensive Care Unit of Nara Prefectural Nara Hospital, Perinatal Medical Center at some point during a 17-mo period between July 1996 and November 1997. Both of the above two infants died soon after birth. Patients with a lungto-body weight ratio of $1.2 \%$ or higher were defined as belonging to the normal group, and those with a ratio of less than $1.2 \%$ were defined as belonging to the pulmonary hypoplasia 
group (4). Written informed consent was obtained from parents of all the infants at the same time of autopsy agreement.

Immunological Staining of $\boldsymbol{S P}-\boldsymbol{A}$. After fixing cadavers in $10 \%$ formalin, autopsied lung tissues were embedded in paraffin, sliced thin $(3 \mu \mathrm{m})$, and subjected to immunohistological SP-A staining by the direct staining method. Specifically, each section was processed as follows: methanol containing $0.3 \%$ hydrogen peroxide; $10 \mathrm{mM}$ citric acid buffer ( $\mathrm{pH}$ 6.0) in an autoclave; $2 \%$ horse serum (blocking); and peroxidase-labeled murine anti-human SP-A MAb $(300 \mu \mathrm{g} / \mathrm{mL}$; Teijin, Tokyo, Japan) overnight at $4^{\circ} \mathrm{C}$. Next, the peroxidase activity was intensified using peroxidase-conjugated anti-peroxidase antibody included in the ER-ICA kit (Abbott Laboratories, Abbott Park, IL, U.S.A.) at room temperature for $30 \mathrm{~min}$, and then $0.05 \mathrm{M}$ Tris buffer (pH 7.6) containing $0.05 \%$ diaminobenzidine- $4 \mathrm{HCl}$ and $0.01 \%$ hydrogen peroxide for $1-2 \mathrm{~min}$. Finally, a hematoxylin counterstain was added.

Assessment Based on the Staining Intensity of SP-A. The expression of SP-A was assessed as one of four grades based on the mean staining intensity of five visual fields. In particular, the staining intensity of SP-A in the lung of a mature infant, without pulmonary lesions, who died soon after birth (gestation period: $37 \mathrm{wk}$, birth weight: $3,150 \mathrm{~g}$, died of severe fetal anemia within $2 \mathrm{~h}$ of birth) was defined as $2+$. The remaining three grades were defined as follows: $1+=$ sporadic staining of alveoli in each visual field; $\pm=$ slight staining in the localized areas of alveoli; and $-=$ almost no staining. Blind assessments of immunological staining intensity of SP-A were carried out by two investigators on each case three times without any clinical information, and the final estimation was reproducible. Artificial pulmonary surfactant (Surfacten ${ }^{\circledR}$, S-TA; Mitsubishi-Tokyo Pharmaceuticals, Inc., Tokyo, Japan) was administered to one infant in the normal group (case 5) and three infants in the pulmonary hypoplasia group (cases 9, 13, and 16). Given that Surfacten contains SP-B and SP-C, but no SP-A, we concluded that the present SP-A antibody staining method was capable of assessing endogenous surfactant production regardless of Surfacten administration.

Assessment of Pulmonary Maturity. The anatomical maturity of lungs was assessed in terms of RAC. Histological sections of lung were examined and radial alveolar counts were made according to the line intersect method (5). A perpendicular line was drawn from a terminal bronchiole to the nearest septal division or pleural surface and the number of alveolar septae intersected by the line were counted.
Statistical Analysis. Differences between the two groups were analyzed using a $\chi^{2}$ test. Correlations between two variables were analyzed using Pearson's correlation coefficients, and $p<0.05$ was considered significant.

\section{RESULTS}

Summary of Subjects. Eight infants were classified as belonging to the normal group (five boys and three girls, cases $1-8$ ), and eight as belonging to the pulmonary hypoplasia group (three boys and five girls, cases 9-16). Tables 1 and 2 summarize the background factors of the above two groups, respectively. No significant differences were observed in terms of gestational age or birth weight between the two groups. In addition, there were no significant differences in Apgar scores between the two groups, but the lung-to-body weight ratio was significantly lower for the pulmonary hypoplasia group $(p<$ $0.01)$.

Clinical Features and SP-A Staining in the Normal Group. In five infants without pulmonary lesions in the normal group (cases 1, 3, 6, 7, and 8), a staining intensity of $1+$ or above was assessed. Case 2 was complicated by marked intrauterine growth retardation $(-3.0 \mathrm{SD})$ and multiple malformation. Despite the fact that this infant lived for $5 \mathrm{~d}$ after birth, a \pm staining intensity of SP-A was assessed. Case 4 was complicated by bilobed right lung and hydramnion, and a - staining intensity was assessed. In case 5, despite 34 wk of gestation, this infant had RDS, and a - staining intensity was assessed (Table 3).

Clinical Features and SP-A Staining in the Pulmonary Hypoplasia Group. Six of the eight infants in the pulmonary hypoplasia group were complicated not only by pulmonary hypoplasia, but also by amniotic fluid volume abnormalities or an anatomical malformation. In contrast to case 14, where pulmonary hypoplasia was relative mild, the staining intensity of SP-A was assessed \pm or less in the remaining seven infants. Three infants (cases 12, 15, and 16) were complicated by congenital diaphragmatic hernia and hydramnion. The gestational age was $38 \mathrm{wk}$ for cases 15 and 16, but the expression of SP-A was low in both cases. In case 15 , no difference in the staining intensity of SP-A was observed between the healthy right lung $(5.0 \mathrm{~g})$ and the affected left lung $(0.5 \mathrm{~g})$ (Table 4).

Effects on the Length of Storage on the Staining Intensity of $S P$ - $A$. The length of storage was within 5 y in 9 of the 16 cases (range: 2 mo to 3 y and $6 \mathrm{mo}$ ); $6-10 \mathrm{y}$ in 3 cases (case 1: $9 \mathrm{y}$ and

Table 1. Summary of the normal group

\begin{tabular}{|c|c|c|c|c|c|c|}
\hline Case & Sex & $\begin{array}{c}\text { Gestational } \\
\text { age (wk) }\end{array}$ & $\begin{array}{l}\text { Birth weight } \\
\text { (g) }\end{array}$ & $\begin{array}{c}\text { 1-min } \\
\text { Apgar score }\end{array}$ & $\begin{array}{c}\text { 5-min } \\
\text { Apgar score }\end{array}$ & $\begin{array}{c}\text { Lung-to-body } \\
\text { weight ratio }(\%)\end{array}$ \\
\hline 1 & Female & 31 & 1,210 & 5 & 10 & 2.6 \\
\hline 2 & Male & 32 & 792 & 9 & 9 & 1.9 \\
\hline 3 & Male & 32 & 2,552 & 0 & - & 2.1 \\
\hline 4 & Male & 34 & 1,850 & 2 & 5 & 1.4 \\
\hline 5 & Female & 34 & 1,900 & 8 & - & 2.4 \\
\hline 6 & Male & 35 & 1,810 & 2 & 5 & 1.5 \\
\hline 7 & Female & 35 & 2,820 & 1 & 1 & 2.1 \\
\hline 8 & Male & 37 & 3,150 & 1 & 1 & 1.6 \\
\hline Mean $\pm \mathrm{SD}$ & $\mathrm{M} / \mathrm{F}=5 / 3$ & $33.8 \pm 2.0$ & $2,011 \pm 797$ & $3.5 \pm 3.4$ & $5.2 \pm 3.8$ & $1.9 \pm 0.4$ \\
\hline
\end{tabular}


Table 2. Summary of the pulmonary hypoplasia group

\begin{tabular}{|c|c|c|c|c|c|c|}
\hline Case & Sex & $\begin{array}{l}\text { Gestational } \\
\text { age (wk) }\end{array}$ & Birth weight $(\mathrm{g})$ & $\begin{array}{c}\text { 1-min } \\
\text { Apgar score }\end{array}$ & $\begin{array}{c}\text { 5-min } \\
\text { Apgar score }\end{array}$ & $\begin{array}{c}\text { Lung-to-body } \\
\text { weight ratio (\%) }\end{array}$ \\
\hline 9 & Female & 22 & 402 & 0 & 3 & 0.75 \\
\hline 10 & Male & 28 & 638 & 0 & - & 0.74 \\
\hline 12 & Female & 31 & 2,346 & 0 & - & 0.40 \\
\hline 13 & Female & 33 & 2,240 & 2 & 2 & 1.19 \\
\hline 14 & Male & 33 & 2,575 & 6 & - & 1.05 \\
\hline Mean \pm SD & $\mathrm{M} / \mathrm{F}=3 / 5$ & $31.5 \pm 5.3$ & $1,858 \pm 1,064$ & $1.5 \pm 2.0$ & $1.6 \pm 0.9$ & $0.8 \pm 0.3$ \\
\hline
\end{tabular}

Table 3. Clinical features and surfactant apoprotein-A staining in the normal group

\begin{tabular}{|c|c|c|c|c|c|c|c|}
\hline Case & Diagnosis & RDS & $\begin{array}{l}\text { Amniotic } \\
\text { fluid volume }\end{array}$ & PROM & $\begin{array}{l}\text { Survival } \\
\text { period }\end{array}$ & $\mathrm{RAC}$ & $\begin{array}{l}\text { SP-A } \\
\text { staining }\end{array}$ \\
\hline 1 & NEC & No & Normal & No & $3 \mathrm{~d}$ & 3.0 & $1+$ \\
\hline 2 & $\begin{array}{l}\text { IUGR, TTTS, PDA, multiple } \\
\text { malformation }\end{array}$ & No & Normal & No & $5 \mathrm{~d}$ & 2.9 & \pm \\
\hline 3 & Fetal hydrops & Unclear & Normal & No & $\begin{array}{l}\text { At } \\
\text { delivery }\end{array}$ & 2.9 & $2+$ \\
\hline 4 & $\begin{array}{l}\text { Holoprosencephaly, bilobed right } \\
\text { lung, pulmonary hemorrhage }\end{array}$ & Unclear & Hydramnion & No & $2 \mathrm{~h}$ & 5.6 & - \\
\hline 6 & Multiple malformation & Unclear & Normal & No & $1 \mathrm{~h}$ & 6.4 & $1+$ \\
\hline 7 & Endomyocardial fibroelastosis & Unclear & Normal & Unclear & $1 \mathrm{~h}$ & 6.3 & $1+$ \\
\hline 8 & Fetal anemia & No & Normal & No & $2 \mathrm{~h}$ & 6.6 & $2+$ \\
\hline
\end{tabular}

NEC, necrotizing enterocolitis; IUGR, intrauterine growth retardation; TTTS, twin to twin syndrome; PDA, patent ductus arteriosus; PROM, premature rupture of the membranes.

Table 4. Clinical features and surfactant apoprotein-A staining in the pulmonary hypoplasia group

\begin{tabular}{|c|c|c|c|c|c|c|c|}
\hline Case & Diagnosis & RDS & $\begin{array}{c}\text { Amniotic } \\
\text { fluid volume }\end{array}$ & PROM & $\begin{array}{l}\text { Survival } \\
\text { period }\end{array}$ & RAC & $\begin{array}{l}\text { SP-A } \\
\text { staining }\end{array}$ \\
\hline 9 & RDS & Yes & Normal & No & $24 \mathrm{~h}$ & 1.8 & \pm \\
\hline 10 & Dry lung syndrome & Unclear & Oligoamnion & Yes & At delivery & 3.4 & \pm \\
\hline 12 & $\mathrm{CDH}$, TOF, Arnold-Chiari syndrome & Unclear & Hydramnion & No & At delivery & 3.9 & \pm \\
\hline 13 & Type II Potter, TOF & Yes & Oligoamnion & No & $24 \mathrm{~h}$ & 4.1 & - \\
\hline 14 & Congenital polycystic kidney & Yes & Normal & Unclear & $90 \mathrm{~min}$ & 2.8 & $1+$ \\
\hline 16 & $\mathrm{CDH}$ & No & Hydramnion & No & $45 \min$ & 6.6 & - \\
\hline
\end{tabular}

$\mathrm{CDH}$, congenital diaphragmatic hernia; TOF, Tetralogy of Fallot; IUGR, intrauterine growth retardation; PROM, premature rupture of the membranes.

$3 \mathrm{mo}$; case 3: 6 y and $2 \mathrm{mo}$; case 11: 6 y and $2 \mathrm{mo}$ ); and more than $10 \mathrm{y}$ in 3 cases (case 5: $15 \mathrm{y}$; case 12: $13 \mathrm{y}$ and $4 \mathrm{mo}$; and case 14: $21 \mathrm{y}$ and $5 \mathrm{mo}$ ). However, there was no correlation between storage period and the staining intensity of SP-A. In case 13, which had the shortest storage period (pulmonary hypoplasia group, storage period: $2 \mathrm{mo}$ ), the staining intensity of SP-A was -, whereas in case 14, which had the longest storage period (21 $\mathrm{y}$ and $5 \mathrm{mo}$ ), the staining intensity was $1+$.

Anatomical Maturation of the Lung. The mean RAC for the normal group was $4.8 \pm 1.7$, and that for the pulmonary hypoplasia group was $4.1 \pm 1.7$. Thus, there were no significant differences between the two groups. The correlation between gestational age and RAC for the normal group was very high at $0.939(p=0.0001)$, whereas that for the pulmonary hypoplasia group was also high at $0.890(p=0.0015)$.

Relationship Between the Staining Intensity of SP-A and Each Background Factor. We analyzed the relationship between the staining intensity of SP-A $(\geq 1+$ or $\leq \pm)$ and each of the following background factors: sex, gestational age, birth weight, Apgar score, pulmonary hypoplasia, amniotic fluid volume, RAC, survival period, malformation, RDS, and premature rupture of the membranes (PROM). The results confirmed a significant negative correlation between the staining intensity of SP-A and two factors: pulmonary hypoplasia and abnormal amniotic fluid volume. No other statistically significant correlations were found (Table 5).

\section{DISCUSSION}

In recent years, the structure and function of SP-A have increasingly become clarified, and the results have shown that SP-A accelerates the intake of phospholipids by type II alveolar epithelial cells and controls the secretion of surfactants. Furthermore, SP-A is essential for the maintenance of the latticelike structure of lamellar inclusion bodies, which are secreted from type II alveolar epithelial cells. This latticelike 
Table 5. Correlation between the staining intensity of surfactant apoprotein- $A$ and various factors

\begin{tabular}{llll}
\hline \multicolumn{1}{c}{ Item } & \multicolumn{1}{c}{ Contents } & $n$ & \multicolumn{1}{c}{$\chi^{2}$ test } \\
\hline Sex & Male/female & $8 / 8$ & $p=0.3017$ \\
Gestational duration & $\geq 32 \mathrm{wk} /<32 \mathrm{wk}$ & $11 / 5$ & $p=0.3296$ \\
Birth weight & $\geq 1500 \mathrm{~g} /<1500 \mathrm{~g}$ & $11 / 5$ & $p=0.3296$ \\
1-min Apgar value & $\geq 4 \mathrm{points} /<3$ points & $4 / 12$ & $p=0.5510$ \\
5-min Apgar value & $\geq 4$ points $/<3$ points & $4 / 7$ & $p=0.4773$ \\
Pulmonary hypoplasia & Yes/no & $8 / 8$ & $p=0.0389^{*}$ \\
Amniotic fluid volume & Normal/abnormal & $9 / 7$ & $p=0.0063 \dagger$ \\
Radial alveolar count & $\geq 4.0 /<4.0$ & $8 / 8$ & $p=0.6958$ \\
Survival period & $\geq 24 \mathrm{~h} /<24 \mathrm{~h}$ & $5 / 11$ & $p=0.3296$ \\
Malformation & Yes $/$ no & $8 / 8$ & $p=0.3017$ \\
RDS & Yes/no & $5 / 5$ & $p=0.4902$ \\
PROM & Yes/no & $3 / 11$ & $p=0.2165$ \\
\hline
\end{tabular}

PROM, premature rupture of the membranes.

$* p<0.05 ; \dagger p<0.01$.

structure is thought to play an important role in the expression of surface activity. In addition, SP-A binds to pathogenic microorganisms that invade the alveoli, and then acts in a similar manner as opsonin to activate alveolar macrophage (6, 7). Furthermore, hemolytic group-B streptococcal infection exacerbates in SP-A deficient mice (8).

SP-A begins to appear in bronchial epithelial cells during the 15 th week of gestation, and in alveoli at approximately wk 23 of gestation. Next, at roughly 31 wk of gestation, sufficient amounts of SP-A are expressed in type II alveolar epithelial cells (9).

The present study findings showed that the staining intensity of SP-A was high at $1+$ or stronger in five infants with a gestational duration of at least $31 \mathrm{wk}$, but that these lungs were free of pulmonary lesions and pulmonary hypoplasia. In addition, SP-A was not detected in infants complicated by RDS. On the other hand, SP-A expression was significantly reduced in infants complicated by pulmonary hypoplasia in all cases except for one infant with normal amniotic fluid volume and relatively mild pulmonary hypoplasia. We consider that the reason we were unable to detect a significant correlation between SP-A expression and birth weight was the small number of cases where the gestational age was less than $32 \mathrm{wk}$.

In terms of the relationship between amniotic fluid volume and SP-A, Asabe et al. (10) found in a study using rabbits that when the amniotic fluid volume was reduced by shunting, not only hypoplasia of the fetal lungs was present, but also reduced numbers of SP-A positive type II alveolar epithelial cells and suppressed SP-A expression. This findings suggested that oligoamnion deters the maturation of fetal lungs and type II alveolar epithelial cells. Furthermore, Nakamura et al. (11) reported that in light of observed alterations to the structure of disaturated phosphatidyl-choline, which is an indicator of surfactant phospholipid and is produced specifically in type II alveolar epithelial cells, qualitative changes in surfactants must have occurred. In the present study, we observed abnormal amniotic fluid volume levels in a total of seven infants: three cases of oligoamnion (cases 10,11, and 13) and four cases of hydramnion (cases 4, 12, 15 and 16). SP-A expression was reduced in all cases irrespective of the volume of the amniotic fluid. Six of seven infants had pulmonary hypoplasia, whereas
SP-A was not detected in one infant with hydramnion, but no pulmonary hypoplasia.

RAC is a useful indicator of the anatomical maturity of the lung (12), and the severity of pulmonary hypoplasia (13). In addition, RAC has been reported to correlate well with gestational age (14). In the present study, we used lung-to-body weight ratio to diagnose pulmonary hypoplasia, and found that regardless of pulmonary hypoplasia, there was a strong correlation between RAC and gestational age. Actually, even in the pulmonary hypoplasia group, and even in cases where the weight of the lung indicated hypoplasia, the degree of its microscopic anatomical maturation corresponded to gestational age. We suggest that RAC is an useful marker of the microscopic anatomical maturity of the lung, but the diagnosis of pulmonary hypoplasia should be made by lung-to-body weight ratio.

In terms of the relationship between RDS and SP-A, measuring the level of SP-A in the amniotic fluid (15), gastric juice, or respiratory aspirate (16) has been shown to be a useful predictor of the onset of RDS. In the present study, an RDS test was conducted on a total of 10 infants: 4 in the normal group and 6 in the pulmonary hypoplasia group. In the normal group, SP-A was not detected in one infant complicated by RDS (case 5 ), but was detected (intensity of $1+$ or higher) in infants not complicated by RDS (cases 1, 2, and 8). In the pulmonary hypoplasia group, the staining intensity of SP-A was assessed $1+$ in one infant complicated by RDS (case 14 ), and \pm or less in infants not complicated by RDS (cases 11 and 16). Therefore, no particular tendency was seen between RDS and staining intensity of SP-A.

In congenital diaphragmatic hernia, a decrease in the expression of SP-A has been shown to deter the structural growth of affected lungs and the functional growth of type II alveolar epithelial cells (17). In the present study, we observed reduced SP-A expression in all three infants complicated by congenital diaphragmatic hernia (cases 12, 15, and 16). These three infants also had hydramnion, and in cases 15 and 16, the expression of SP-A was reduced despite a 38 -wk gestational age. In case 15, both the healthy (right) and affected (left) lungs were examined. However, no difference was observed in the staining intensity of SP-A between the two lungs.

Generally speaking, the longer the storage period of samples was, the weaker the immunological staining intensity was. In the present study, the staining intensity in case 14, which had the longest storage period ( $21 \mathrm{y}$ and $5 \mathrm{mo}$ ), was $1+$. Therfore, the staining intensity of SP-A using our methods could be assessed after several years' storage.

We demonstrated immunohistologically using murine antihuman SP-A MAb that the expression of intrapulmonary SP-A in hypoplastic lungs decreased. We concluded that the functional maturity of the lungs of infants with pulmonary hypoplasia was also suppressed.

\section{REFERENCES}

1. Hawgood S, Clements J 1990 Pulmonary surfactant and its apoproteins. J Clin Invest $86: 1-6$

2. Hallman M, Arjomaa P, Mizumoto M, Akino T 1988 Surfactant proteins in the diagnosis of fetal lung maturity: I. Predictive accuracy of the $35 \mathrm{kD}$ protein, the 
lecithin/sphimgomyelin ratio, and phosphatidylglyserol. Am J Obstet Gynecol 158:531-535

3. Eguchi H, Koyama N, Tanaka T, Kamiya K, Ogawa Y 1991 Surfactant apoprotein A (SP-A) in tracheal aspirates of newborn infants with RDS. Acta Pediatr Jpn 33:649654

4. Askenazi SS, Perlman M 1979 Pulmonary hypoplasia: lung weight and radial alveolar count as criteria of diagnosis. Arch Dis Child 54:614-618

5. Emery JL, Mithal A 1960 The number of alveoli in the terminal respiratory unit of man during late intrauterine life and childhood. Arch Dis Child 35:544-547

6. van Iwaarden JF, Welmers B, Verhoef J, Haagsman HP, van Golde LMG 1990 Pulmonary surfactant protein A enhances the host defense mechanism of rat alveolar macrophages. Am J Respir Cell Mol Biol 2:91-98

7. van Iwaarden JF, van Strijp JAG, Ebskamp MJM, Welmers AC, Verhoef J, van Golde LMG 1991 Surfactant protein A is opsonin in phagocytosis of herpes simplex virus type 1 by rat alveolar macrophages. Am J Physiol 261:L204-L209

8. LeVine AM, Bruno MD, Huelsman KM, Ross GF, Whitsett JA 1997 Surfactant protein A-deficient mice are susceptible to group B streptcoccal infection. J Immunol 158:4336-4340

9. Toki N, Sueishi K, Minamitani M, Maeda H, Nakano H, Suzuki Y 1995 Immunohistochemical distribution of surfactant apoproteins in hypoplastic lungs of nonimmunologic hydrops fetalis. Hum Pathol 26:1252-259

10. Asabe K, Toki N, Hashimoto S, Suita S, Sueishi K 1994 An immunohistochemical study of the expression of surfactant apoprotein in the hypoplastic lung of rabbit fetuses induced by oligohydramnios. Am J Pathol 45:631-639
11. Nakamura Y, Yamamoto I, Funatsu Y, Motomura K, Fukuda S, Hashimoto T, Morimatsu M 1988 Decreased surfactant level in the lung with oligohydramnios: a morphometric and biochemical study. J Pediatr 112:471-474

12. Reale FR, Esterly JR 1973 Pulmonary hypoplasia - a morphometric study of the lungs of infants with diaphragmatic hernia, anencephaly and renal malformation. Pediatr 51:91-96

13. Askenazi SS, Perlman M 1979 Pulmonary hypoplasia: lung weight and radial alveolar count as criteria of diagnosis. Arch Dis Child 54:614-618

14. Betz P, Nerlich A, Bussler J, Hausmann R, Eisenmenger W 1997 Radial alveolar count as a tool for the estimation of fetal age. Int J Legal Med 110 $52-54$

15. Satoh K, Sakata H, Nishijima S, Fujimoto S, Koga Y, Nakano H, Maeda H, Matsumoto N, Nakabayashi M, Takagi K, Higuchi M, Gotoh K. Hirano H, Kuroki Y, Akino T 1992 Assessment of fetal lung maturity using newly developed immunological measurement of fetal pulmonary surfactant apoprotein-A in amniotic fluid. Acta Obstet Gynecol Jpn 44:1269-1276

16. Chida S, Phelps DS, Cordle C, Soll R, Floros J, Taeusch HW 1988 Surfactantassociated proteins in tracheal aspirates of infants with respiratory distress syndrome after surfactant therapy. Am Rev Respir Dis 137:943-947

17. Asabe K, Tsuji K, Handa N, Kurosaka N, Kajiwara M 1997 Immunohistochemical distribution of surfactant apoprotein-A in congenital diaphragmatic hernia. J Pediatr Surg 32:667-672 